\title{
Indicator use in soil remediation investments Views from policy, research and practice
}

\section{Potential indicators for investment analysis}
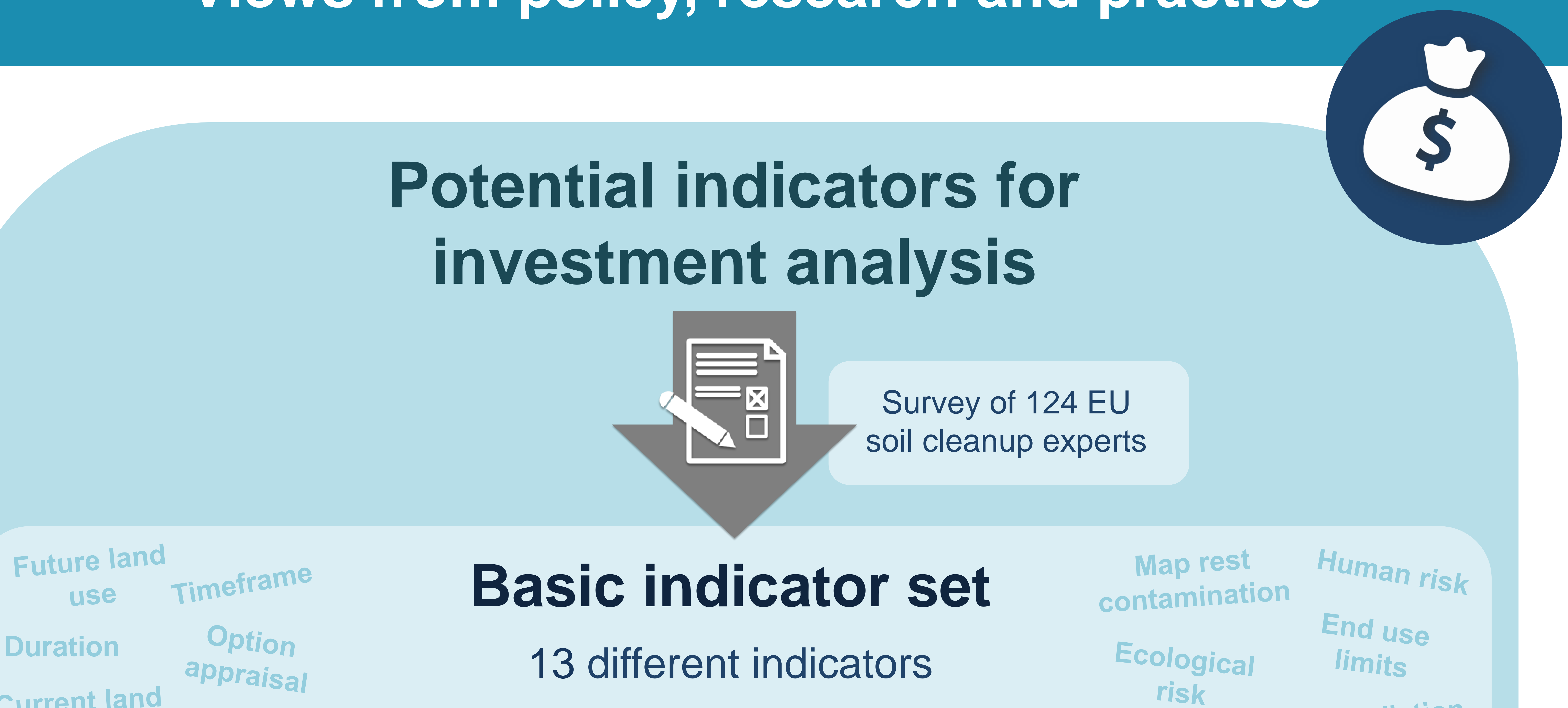

Basic indicator set

13 different indicators

Topics cover practical limitations, starting situation,

use

success success environmental risk, visualization and uncertainty and boundaries

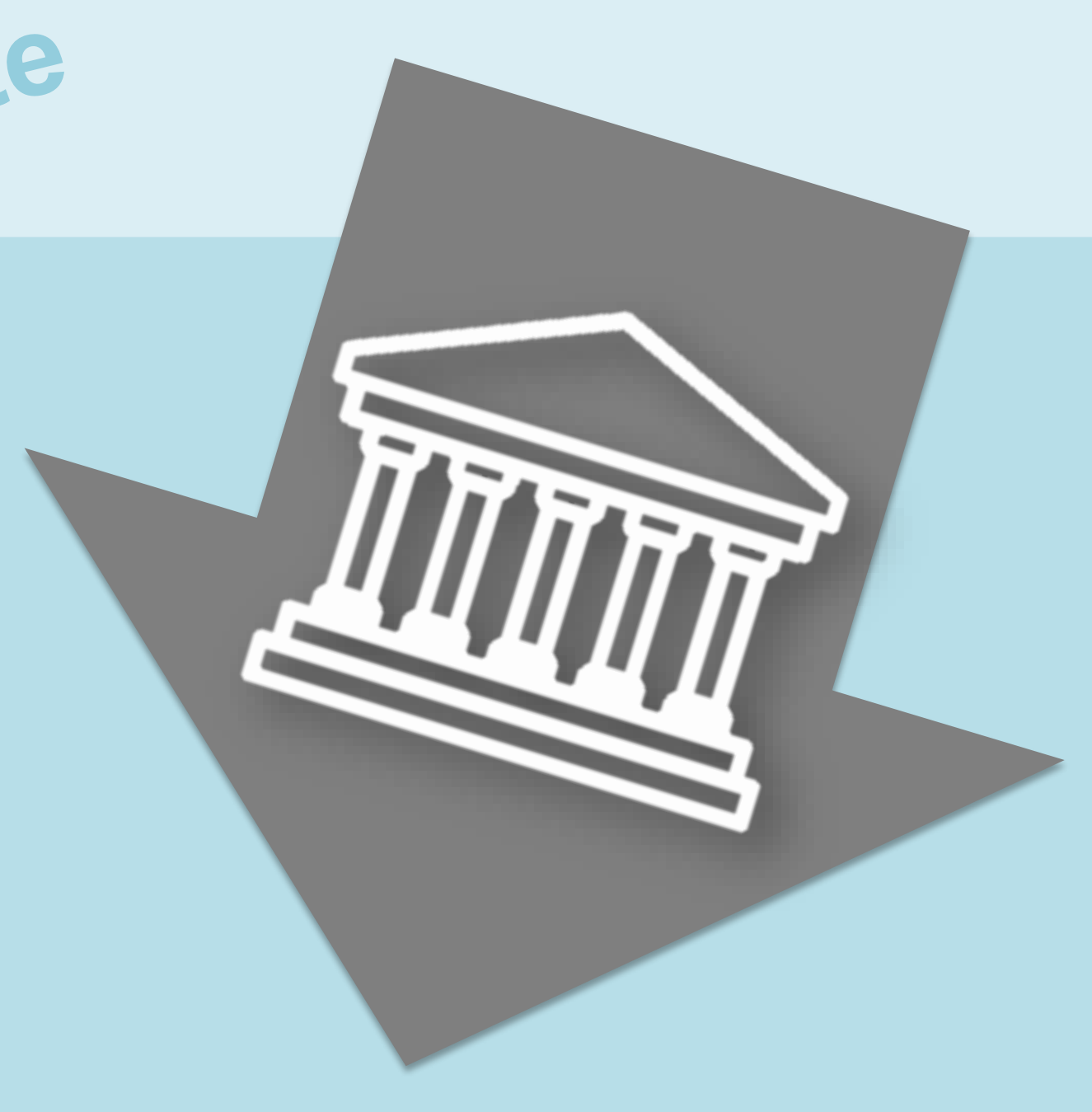

POLICY

\section{+1 to 6 indicators}

- Indicators concerning site valuation

- Reflect importance of site redevelopment

- Social profitability is also addressed

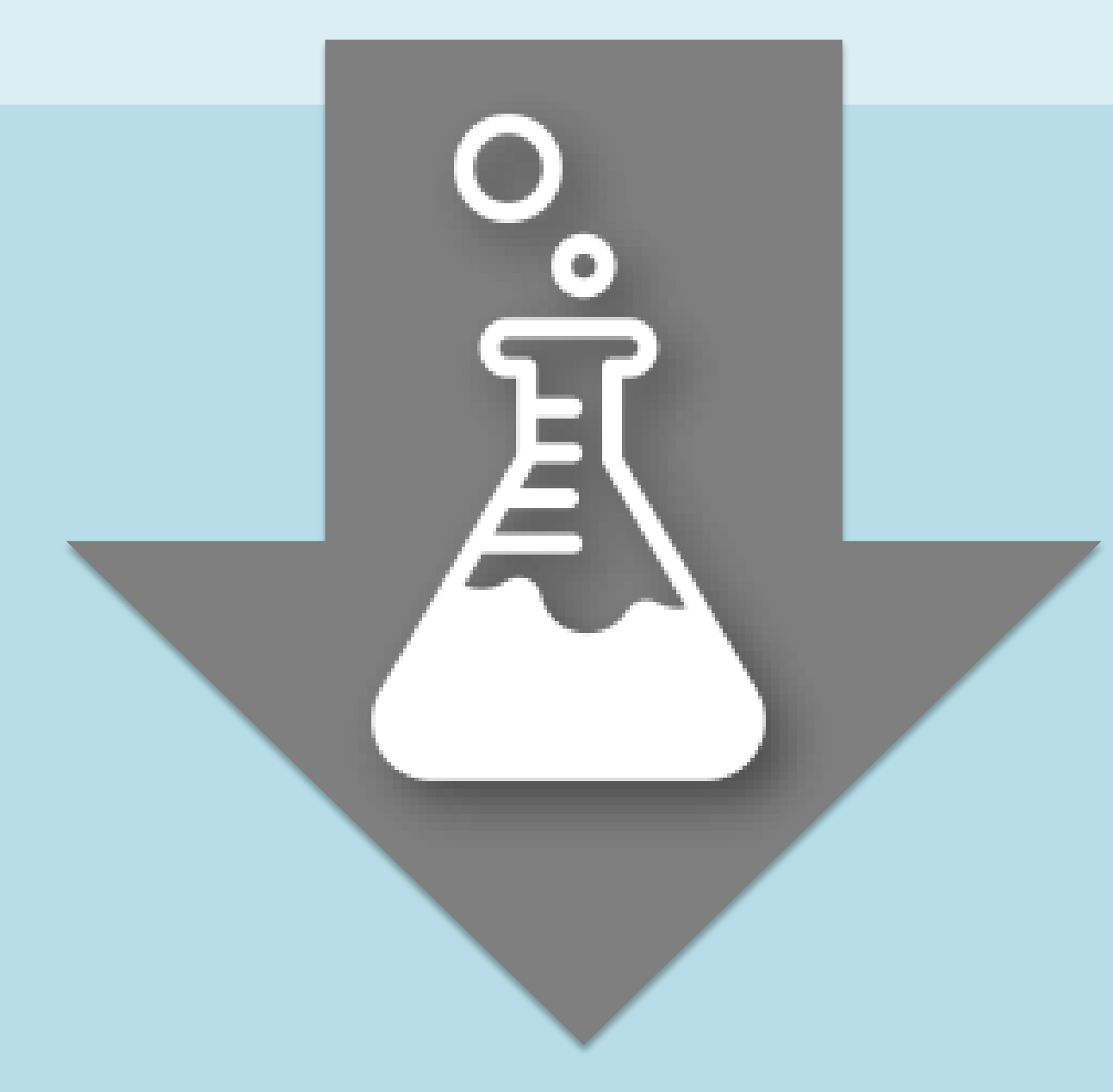

RESEARCH

\section{+5 to 15 indicators}

- Most extensive set of indicators

- Extensive range of broad and detailed indicators

- Principles of sustainability

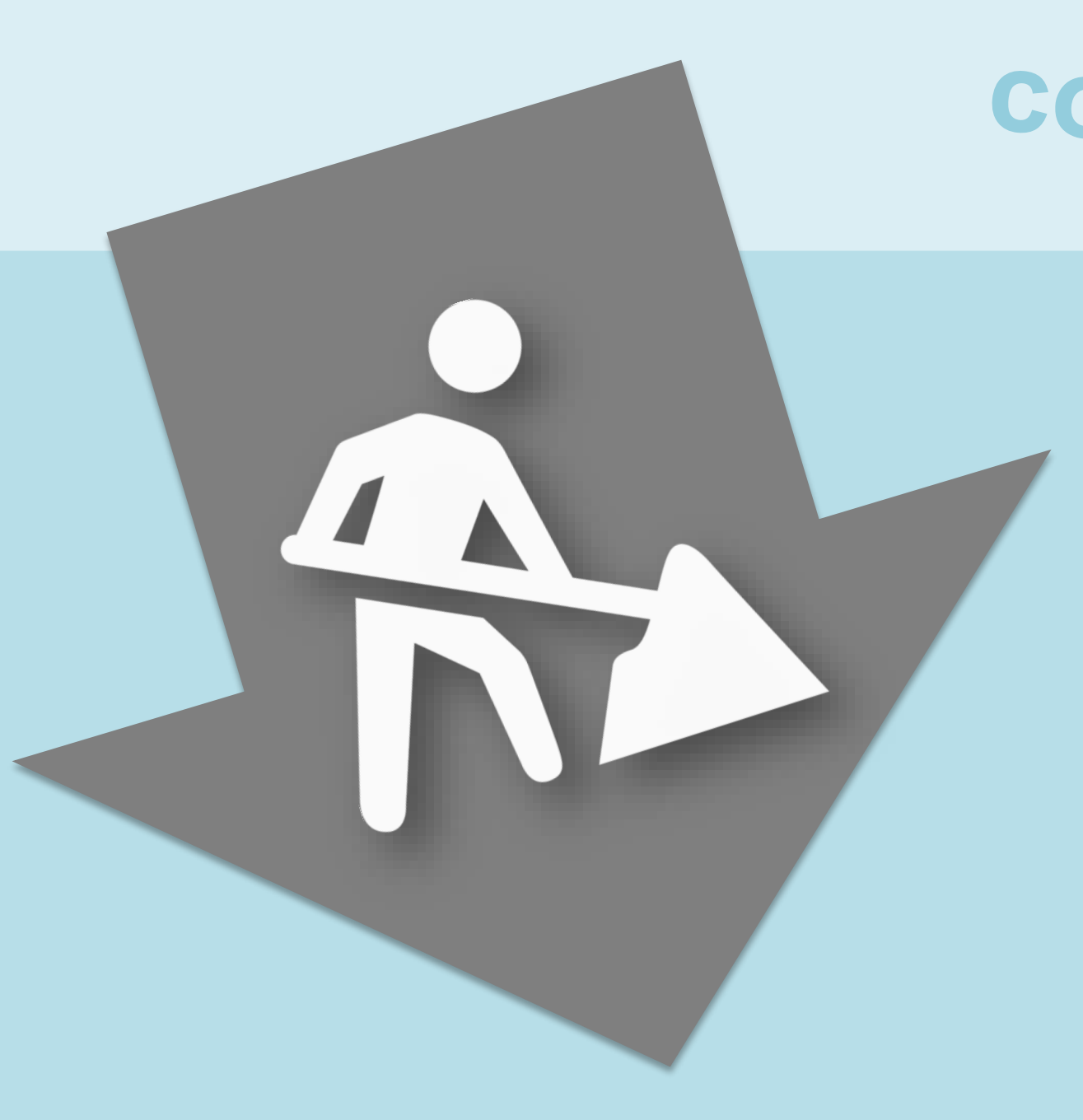

\section{PRACTICE}

\section{+0 to 8 indicators}

- Mainly field analyses, feasibility and restrictions

- Indicators concerning local residents

- Surprisingly no profitability indicator

\section{Additional insights}

- More interest in environmental and financial indicators than social indicators

- All groups see the inclusion of stakeholders as less important

- Soil remediation projects can be improved by adding indicators on site value, local support, site surroundings and a social CBA

\section{Lies Huysegoms}

Ph.D. fellowship of the Research Foundation - Flanders (FWO) - lies.huysegoms@kuleuven.be 